\title{
Enhancing sustainability by integrated use of wood and natural fibers for energy, chemical feedstock and advanced materials
}

\begin{abstract}
To achieve a sustainable future, our evolving global society needs to embrace the concept of Integrated Biomass Technologies. Such a systematic use of renewable bio-resources to meet our needs could promote resource sustainability while at the same time maximizing feedstock values, product performance, and increased total profitability in either or both the agriculture and forest products industries. The fundamental principles of Integrated Biomass Technologies include biorefining to produce biofuels, bio-based chemical feedstocks, bioenergy, and cellulose nano-fibers, using problematic, waste or under-valued biomass as a direct source of electrical energy, and for developing advanced wood and biocomposite materials to engineer advanced structures. These fundamental principles provide a global roadmap to biobased economies based on the systematic use of many under-valued lignocellulosic resources to produce liquid biofuels, energy, chemical feedstocks, and advanced materials. Implementation of Integrated Biomass Technologies could lead to a more sustainable global society.
\end{abstract}

Keywords: sustainability, biomass, biocomposites, wood composites, biorefinery, energy from biomass, forest products, agricultural residues
Volume 2 Issue 2 - 2018

\author{
Jerrold Winandy \\ Department of Bioproducts and Biosystems Engineering, \\ University of Minnesota, USA
}

Correspondence: Jerrold EWinandy, Department of Bioproducts and Biosystems Engineering, University of Minnesota, 2004 Folwell Ave, St. Paul, MN 55I08, USA, Tel + 76343493 65,Email jwinandy@umn.edu

Received: February 21, 2018| Published: March 13, 2018

\section{Introduction}

Today, our economies and our societies suffer from the base problems of too much demand for finite resources by too many people. Globally, a vast lignocellulosic resource (biomass) is available for industrial use, but virtually everyone now recognizes that it must be used in both an efficient and sustainable manner. ${ }^{1-3}$ This bio-resource includes all lignocellulosic from both woody and agricultural fibers to post-agricultural crop residues to recycled paper, timber and wood and biocomposites. ${ }^{4}$ The concept of Integrated Biomass Technologies (IBT) provides for a systematic approach to meet global userconsumer needs for fuels, chemicals, and construction materials from an ever-changing array of many diverse under-valued lignocellulosic resources. Adoption of IBT processing then allows industry to 1) adapt to ever-changing nature and availability of forest and lignocellulosic feed-stocks, 2) use market-driven models to determine the best use of resources on the basis of current market prices for various commodities, 3) modify production of chemical feedstocks, transportation fuels, and advanced products in accordance with these models, 4) adjust raw materials and manufacturing processes to maximize the profit and product performance, 5) develop new markets for innovative products, and 6) ensure that products meet structural, fire, and durability requirements for residential and commercial structures. The concept of IBT also helps land and forest managers improve agricultural and forest health by working collaboratively with industry to remove less-desirable biomass and thereby offset the costs associated with efforts to restore damaged eco-systems. Three new tenets of sustainable processing need to be implemented in any IBT approach: biorefining, energy from biomass, and advanced biocomposite products.

\section{Biorefinery}

Biorefining could be the first step in applying an IBT approach. Bio-refining encompasses the use of all components of biomass to yield products, such as liquid transportation fuels and chemical feedstocks. ${ }^{5,6}$ Bio-refineries offer the potential for off-setting the cost of forest management, decreasing dependence on fossil fuels, and mitigating production of greenhouse gases. ${ }^{1}$

Biofuels derived from biomass are generally regarded as greenhouse-gas neutral because the amount of $\mathrm{CO}_{2}$ released on combustion equals the amount adsorbed from the atmosphere and sequestered by the plant through photosynthesis. ${ }^{5}$ As concerns over global warming and greenhouse gas generation rise, governments around the world are increasing support for fuels from biomass. This then may give more confidence for private investment in biomaterials for energy. This is an exciting time as many scientific, social, natural resource, political, and economic considerations seem to be aligning to create an environment for producing transportation fuel, chemical feedstocks and advanced biocomposite products from biomass.

When considering using lignocellulosics to act as feedstocks for producing chemicals, the concept is not new. ${ }^{7}$ Before petroleum and petroleum-based chemistries became commonplace, wood and biomass were the primary source of chemicals. Today, the increased cost of fossil fuels has renewed interest in using lignocellulosics from wood and natural biofiber materials for production of transportation fuels, energy directly from biomass and chemical feedstocks. Many processes for converting wood and other biomass resources into liquid fuels and chemical feedstock are again becoming cost competitive. An example of this is the growing interest in development of chemical 
feedstocks for making bio-based plastics, ${ }^{8-10}$ the use of bio-based resins to replace thermoset adhesives for engineered composites,${ }^{11}$ and use of bio-extractives for imparting moisture- or decay-resistance to non-durable wood and biocomposites. ${ }^{12,13}$

There are currently two likely routes for producing chemicals and liquid fuels from biomass. The lignocellulosics can be processed into sugars using chemical and biochemical methods and the sugars are subsequently fermented to ethanol or, the lignocellulosics can be converted thermochemically to pyrolysis oil or product gas and these intermediates further processed to provide liquid fuels or electricity.

Increasing the yield of ethanol from wood and other lignocellulosic materials using chemical systems has been a goal of researchers for many years. Fundamental research on the kinetics of hemicellulose and cellulose hydrolysis led to the "trickle-bed dilute-acid saccharification process" in $1945 .{ }^{14}$ this concept became the basis for the U.S. Department of Energy (DOE) research on "dilute-acid hydrolysis". Today, DOE has largely abandoned this approach in favor of "enzymatic saccharification". The bulk of the research throughout the 1980's and 1990's replaced the second stage of acid hydrolysis with enzymatic saccharification. ${ }^{1,15,16}$

Biochemical and enzyme manufacturers have recently had considerable success in accelerating the saccharification process and reducing the costs of the enzymes, soon these successes will translate into improved ethanol yields or commercial processes. Today, improved commercial-level yields are often recognized as a yet unconquered barrier to widespread implementation. ${ }^{2}$

They note that many agricultural residuals and hardwoods are rich in five carbon sugars or pentoses (xylose, arabanose). For example, xylose is particularly abundant in the hemicellulose of hardwood species (from $12 \%$ to $26 \%$ ) and many grasses. However, xylose and arabinose are considerably harder to ferment than glucose and the other six carbon sugars. Research continues on developing more robust organisms to improve conversion.

There is much less Xylose obtained in hydrolysis of softwoods $(6.6 \%)$, but considerably more mannose $(10 \%)$ and the galactose and arabinose combine for another $5 \% .{ }^{17}$ Six-carbon hemicellulose sugars such as galactose and mannose are fermented by yeasts like S. cerevisiae, with rates and yields with mannose approaching that obtained with glucose. Pretreatment processes to remove hemicellulose can recover $50 \%$ to $90 \%$ of the available hemicellulose sugars in both hardwoods and softwoods. ${ }^{16,18}$

Thermo chemical methods involve heating biomass under controlled conditions. In general, they include gasification or pyrolysis, two processes in which the target product is either a gas or a liquid fuel, respectively. In either process, the goal is to convert complex heterogeneous biomass to simple chemicals using rapid heating of lignocellulosic biomass in an oxygen-depleted environment forms gases, liquids, and solids. The relative proportion of the three components depends on heating rate and temperature. The gas phase is largely hydrogen, methane, carbon monoxide, carbon dioxide, and water. The liquid phase, or pyrolysis oil, contains thousands of compounds, many of which are unstable and polymerize over time. ${ }^{19-21}$ The solid phase, or char, is largely carbon. The product gas produced in gasification can be used in a gas turbine with relatively little cleanup, but for producing other compounds like liquid fuels, the carbon dioxide and water must be removed. This reformulated gas mixture is generally referred to as synthesis gas or syngas.

Use of pyrolysis oils from thermochemical processes has received a lot of attention, yet technical problems have delayed progress. Pyrolysis oil contains a complex mixture of hydrocarbons and hydroxy acids with $10-20 \%$ water. The $\mathrm{pH}$ is typically 1.5 to 3.0 . The resulting liquid is often corrosive and unstable, degassing and polymerizing on storage. Pyrolysis oil cannot be used directly in gasoline or diesel engines, but can be further processed to make transportation fuels or used directly in boilers and other combustion devices.

\section{Energy from biomass}

Another critical concept of the IBT approach involves the direct conversion of biomass to energy. The forest products industry in the United Stated of America (U.S.) uses almost 90 million dry metric tons of wood waste annually for energy. A growing number of energy-producing utilities are also using bio-based materials for fuel by installing agricultural or wood residue gasifiers to convert additional biomass. The gas resulting from this thermal decomposition, especially in wood gasifier technology, is called "product gas" which then replaces the use of natural gas. There is also renewed interest in production of ethanol and other chemicals from wood. The agricultural industry already produces ethanol from corn and sugarcane and has intense interests in both gasification and fermentation processes to make use of the agricultural residuals. At present, the only commercial processes are fermentation of sugarcane and corn kernels to produce ethanol and esterification of crop oils for diesel fuel. To meet increased demand for ethanol, alternate sources of biomass will become necessary and materials such as agricultural and forest residues, corn stover, wheat- or rice-straw, and under-valued wood resources are considered likely alternatives.

It is estimated that 330 million dry metric tons of lignocellulosics are available in the U.S. on a sustainable annual basis and could be used for the production of energy. ${ }^{22}$ Another 545 million dry metric tons of agricultural residuals could also be harvested without reducing the productivity of U.S. agricultural land. Still, the cost and uncertainty associated with delivering this material to commercial biorefineries is a major market-inhibiting factor that determines economic feasibility. Today, most economic models project raw material costs and the costs of its transportation to mill are projected to be greater than $50 \%$ of total operating costs.

\section{Advanced biocomposites}

The next tenant of IBT is advanced biocomposite products that significantly advance both the performance and sustainability biobased natural fiber composites. Biocomposite technologies involve breaking lignocellulosic materials down to smaller elements, such as a flours, fibers, particles, flake/strands, or veneers, then reassembling these elements into biocomposite products using an inorganic, thermoset or thermoplastic binders or by natural fiber-fiber hydrogen bonding. Thousands of innovative bio-based composite products using wood or agricultural fibers or residues, or hybrid systems using any combination of the above are now available..$^{23,24}$ However, users of many of these wood-and bio-composite products commonly refer to the same recurring perceptions of low strength, poor durability and fire resistance. Advanced lignocellulosic composites must be developed that negate such perceptions. Advanced lignocellulosic composites 
must meet the needs of a wide-spectrum of users for high-performance building and commodity products. As importantly, these must be perceived by end-users as representing a critical tool for achieving sustainable forestry and agricultural practices. Biocomposites manufactured from biomass have unique performance, particularly with regard to strength/weight ratio and offer environmental advantages to non-renewable mineral- or petrochemical-based resources. ${ }^{25}$ While it is desirable for lignocellulosic materials used for composites to be uniform and consistent, lignocellulosic materials are known to differ widely among species. For an in-depth review of the composition of lignocellulosic materials. ${ }^{24}$

Agro-based lignocellulosics intended for use in composite products can be categorized into two types: agricultural residues and lignocellulosics grown specifically for their fiber. The residue-types are characterized by species such as sugarcane bagasse, cereal straws, coconut coir, corn or cotton stalks, whereas the later is characterized by species such as jute, kenaf, wood and industrial hemp. The properties and processing of various wood- and agro-based lignocellulosic composites have been reviewed by Irle et al. ${ }^{26}$ and English et al. ${ }^{27}$ respectively.

Many non-wood agricultural fibers that are common worldwide are usually annual crops and available seasonally. The overall limitations for using agricultural-based lignocellulosic materials often include: seasonality of harvest, lack of established delivery systems, processing complications caused by fiber density and morphology, process-temperature limitations, risk of decay, and odor emission during processing and use. ${ }^{25}$ Low thermal-degrade temperatures, potential for high volatile emissions, and high moisture absorption of agro-fibers must be considered in biocomposite processing, but when compared to wood fiber, agro-fibers have lower density, higher stiffness-to-weight ratio and pliability, and enhanced recyclability and biodegradability. ${ }^{1,25}$ Further, while some inorganic fibers such as fiberglass have better mechanical properties, bio-fibers have desirable balance of strength and weight. ${ }^{25}$

The concept of more sustainable global and local economies will be promoted with the development of renewable, recyclable, and reusable materials, but we must also convince governmental policy makers that sustainable biocomposites can also serve as a tool for sustainable economic development. ${ }^{1,28}$ To achieve these dual goals, we must develop the fundamental and applied science and technology necessary to assure resource managers and governmental policy makers that biocomposite technologies do indeed promote sustainability, reduce adverse environmental impacts, and increase economic value-added to users, economies and environments. ${ }^{2}$ We must develop tools to enhance reuse and recyclability, while minimizing the environmental impacts of processing. Then as agricultural- or forest-resource options change, as discarded wood- and bio-fibers from waste-streams become available, as alternative non-wood and non-lignocellulosic materials become more economical, and/or as air- and water-quality regulations change, we can adapt and sustainably address each of these issues.

The next generation of engineered biocomposites needs to provide construction materials and building products that far exceed current performance and serviceability expectations. They need to be lower cost, higher strength, more durable, adaptable, and reliable, lower maintenance, and smarter. Smart materials are able to adapt to changing conditions. For example, we need biocomposites that decrease porosity when dry so that they resist wetting, or increase porosity when wet so that it dry quicker, or that can sense excess mechanical stress or strain and warn users of potential structural problems.

The most promising current technical opportunity for developing advanced biocomposites involves nanocellulose-based performance enhancement of biocomposites..$^{12,29}$ Recent advancements in nanotechnology have recently led to the semi-commercial isolation of nanocrystalline cellulose. ${ }^{12,15}$ While nanocrystalline cellulose may be only $1 / 10^{\text {th }}$ as strong as carbon nanotubes that are currently the strongest known structural material, ${ }^{30,31}$ this nanocrystalline cellulose may cost $50-1000 \mathrm{x}$ less to produce..$^{29,32}$ Engineered biocomposites employing nanocrystalline cellulose reinforcement could soon provide advanced performance, durability, value, service-life, and utility while at the same time being a fully sustainable technology. ${ }^{33}$ Additional research is also needed to combine lignocellulosics with other materials such as Kevlar, polyamides, polyolefin, or fiberglass to produce advanced high-performance materials.

A critical tool to achieve these goals may require using the new science of nanotechnology to manipulate and control materials and processes at the nanoscale. Nanotechnology, if many of its apparent promises can be achieved, may present a tool to improve structural performance and extend serviceability by orders of magnitude. Nanotechnology offers potential opportunities for development of advanced wood- or lignocellulosic-based biocomposites. Then we may be able to exploit opportunities to identify, control, and optimize material and process factors in real-time so as to engineer products having highly specified performance characteristics with both economic and environmental advantages.

We must also address our objectives for a sustainable future and advanced product using integrated approaches that simultaneously provide environmental, utilitarian, and economic advantages. ${ }^{2}$ It now seems that a truly sustainable vision for the use of IBT is now evolving. It may include a series of sequential processing approaches including an initial biorefinery stage to obtain ethanol/biodiesel fuels either thermochemically or biochemically, followed by production of biocomposite or paper-based products from the biorefinery residues, and then production of bio-based electrical energy from biocomposite or paper-mill residues. Such an integrated resource solution is thought by many to offer the optimum long-term solution to meeting both user needs and sustainable development.

To develop advanced biocomposites we must begin to understand fundamental "Materials-Process-Performance" relationships. Then we can develop highly adaptable manufacturing processes to produce advanced biocomposite products that meet consumer needs while simultaneously empowering resource managers to sustainably manage and improve the forest resource. Next, we have to accelerate the use of all lignocellulosics from agricultural and forest sources, especially under-valued residues and problematic invasive species. The challenge will be to meet the needs of growing populations with biocomposites from under-utilized, low- or no-value virgin, or waste biomass materials. We need to work together to encourage the use of our ever-changing wood and lignocellulosic resources by providing baseline data required to allow for the optimal use. ${ }^{34}$

\section{Conclusion}

Exciting new opportunities exist for biorefining to produce 
biofuels, bio-based chemical feedstocks, bioenergy, and cellulose nano-fibers and for developing advanced biocomposite materials, and for engineering advanced structures. This systematic approach for maximizing performance, resource sustainability, and profitability is called Integrated Biomass Technologies. Advanced biocomposite technologies promote the use diverse lignocellulosic feedstocks including timber, woody residues, agricultural fiber, lignocellulosic residues, invasive species, and recycled bio-based materials. It also enhances our ability to use, and adapt with, an ever-changing quality level of wood and/or other natural lignocellulosic feed-stocks for advanced bio-based materials with improved fire- and structuralperformance, and longer service-life.

From a manufacturing and a global-resource sustainability standpoint, with a fundamental understanding of the relationships between materials, processes, and value/performance properties we will soon be able to recognize the attributes and quality of an array of bio-based materials, then adjust our manufacturing and processing systems to produce the highest value-added solution considering an array of social, economic, natural resource, and/or political factors. Thus, as resource properties or availability changes or as economics change, the relative biofuels, biochemicals, biomaterials process streams can be modified to produce the highest value-added solution.

Implementation of the principal concepts of Integrated Biomass Technologies could lead to a global society maintained by sustainable and renewable bio-based technologies rather than a society based on the use of non-renewable, non-sustainable resources. The success and implementation of an Integrated Biomass Technologies approach will depend both on its economic feasibility and our social goals.

\section{Acknowledgement}

None.

\section{Conflict of interest}

Author declares there is no conflict of interest

\section{References}

1. Winandy JE, Rudie AW, Williams RS, et al. Opportunities for using wood and biofibers for energy, chemical feedstocks, and structural applications. In: Pickering KL, editor. Properties and performance of natural-fibre composites. UK: Woodhead Publishing; 2008a. p. $330-355$.

2. Winandy JE, Rudie AW, Williams RS, et al. Integrated Biomass Technologies: A future vision for optimally using wood and biomass. Forest Products Journal. 2008b;58(6):6-16.

3. Walker T, Cardellichio P, Colnes A, et al. Biomass Sustainability and Carbon Policy. USA: Manoment Center for conservation Sciences; 2010:1-182.

4. Linder M, Mees WW, Suominen T, et al. Conducting Sustainability Impact Assessments of Forestry-Wood Chains: examples of ToSIA applications. European Journal of Forest Research. 2012;131(1):21-34.

5. Rudie AW. State of the art in biorefining in Finland and USA. USA: USDA Forest Service, Forest Products Laboratory; 2009:1-27.

6. Nanda S, Azargohar R, Dalai AK, et al. An Assessment of the Sustainability of Lignocellulosic Biomass for Biorefining. Renewable and Sustainable Energy Reviews. 2005;50:925-941.

7. Clark JH, Deswarte F. Introduction to Chemicals from Biomass.
UK: Wiley Publishing; 2015. 311 p.

8. Rowell RM, Sanadi AR, Caulfield DF, et al. Utilization of natura fibers in plastic composites: Problems and opportunities. In: Leao AL, Carvalho FX, et al, editors. Lignocellulosic-Plastics Composites. Brazil: USP \& UNESP; 1997a.

9. Klass DL. Biomass for Renewable Energy, Fuels and Chemicals. USA: Academic Press; 2007. 651 p.

10. Clemons CM, Rowell RM, Plackett D, et al. Wood Composites. In: Rowell RM, editor. Handbook of wood chemistry and wood composites. 2nd ed. USA: CRC Press; 2013:473-508.

11. Frihart C. Wood adhesion and adhesives. In Rowell R, editor. Handbook of wood chemistry and wood composites. 2nd ed. USA: CRC Press; 2013;255-320.

12. Jawaid M, Boufi S, Khalil A. Cellulose-Reinforced Nanofibre composites: Production, properties and applications. UK Woodhead Publishing; 2017. 517 p.

13. Kirker GT, Blodgett AB, Lebow S, et al. Transferable durability: Enhancing decay resistance of non-durable wood species with extractives from durable wood species. Sweden: Proceedings IRG Annual Meeting; 2013:1-12.

14. Harris EE, Berlinger E, Hajny GJ, et al. Wood and its Chemistry. Industrial \& Engineering Chemistry Research. 1945;37:12.

15. USDA. Wood Handbook: Wood as an Engineering Material. USA: USDA Forest Service, Forest Products Laboratory; 2010:1-509.

16. Rudie A, Reiner R, Sutherland NR, et al. Acid prehydrolysis of wood. In: Proceedings of TAPPI engineering, pulping and environmental conference. USA: TAPPI press; $8 \mathrm{p}$.

17. Pettersen RC. Chemical composition of wood. In: Rowell RM, editor. The Chemistry of Solid-Wood. USA: ACS Publication; 1984:57-126.

18. Mansfield SD, Mooney C, Saddler JN. Substrate and enzyme chaacteristics tht Limit Cellulose Hydrolysis. Biotechnology Progress. 1999;15(5):804-816.

19. Evans RJ, Milne TA. Molecular Characterization of the Pyrolysis of Biomass. Energy \& Fuels. 1987;1(4):311-319.

20. Osamaa A, Kuoppala E, Solantausta Y. Fast Pyrolysis of Forestry Residue. II. Physicochemical Composition of the Product Liquid. Energy \& Fuels. 2003;17(2):433-443.

21. Linck M, Felix L, Marker $\mathrm{T}$, et al. Integrated Biomass Hydropyrolysis and Hydrotreating: A brief review. WIRE's energy Environ. 2014;3:575-581.

22. USDA. A Billion Ton Feedstock Supply for the Bioenergy and Bioproducts Industry. USA: U.S. Department of Energy and U.S. Department of Agriculture; 2005:1-78.

23. Youngquist JA, English BE, Spelter H, et al. Agricultural fibers in composition panels. USA: Proceeding of $27^{\text {th }}$ International Particleboard/Composite Materials Symposium; 1993:1-20.

24. Rowell RM, Young RA, Rowell JK. Paper and Composites from Agro-based resources. USA: CRC Press/Lewis Publishers; 1997b. $446 \mathrm{p}$.

25. Clemons CM, Caulfield DF. Natural Fibers. In: Xanthos M, editor Functional fillers for plastics. Germany: Wiley-VCH; 2005:195206.

26. Irle MA, Barbu MC, Reh R, et al. Wood Composites. In: Rowell RM, editor. Handbook of wood chemistry and wood composites. 2nd ed. USA: CRC Press; 2013:321-412. 
27. English B, Chow P, Bajwa DS. Processing composites. In: Rowell R, Young R, et al. editors. Paper and Composites from Agro-based resources. USA: CRC-Lewis Publishers; 1997:269-299.

28. Winandy JE, Wellwood RW, Hiziroglu S. Using wood composites as tool for sustainable forestry: Proceedings of Scientific Session 90, XXII IUFRO World Congress. USA: USDA Forest Service, Forest Products Laboratory; 2005:1-100.

29. Simonsen J. Bio-based nanocomposites: Challenges and Opportunities. Canada: Society of Wood Science and Technology $48^{\text {th }}$ Annual Convention; 2005:1-66.

30. Xanthos M. Modification of Polymer Mechanical and Rheological Properties with Functional Fillers. In: Xanthos M, editor Functional Fillers for Plastics. Germany: Wiley-VCH Verlag; 2005 .
31. Samir MA, Alloin F, Defresne A. Review of Recent Research into Cellulosic Whiskers, their Properties and their Application in Nanocomposites Field. Biomacromolecules. 2005;6(2):612-626.

32. Koo JH. What are Nanoplastics? USA: The Future of Nanoplastics; 2007.

33. Cai Z, Rudie AW, Wegner TH. Integrated Technology for Biobased Composites. In: Christopher L, editor. Green Chemistry-Integrated Forest Biorefineries. UK: Royal Society of Chemistry; 2013:276289.

34. USDOE. International Energy Outlook 2012. USA: US Department of Energy, Energy Information Administration; 2012:1-12. 